\title{
Un ejemplo de mala praxis ambiental: Tekchem en Salamanca, Gto.
}

\author{
Addi Santiago Cruz Méndez a,1, Esaú Ortega Ramírez. ${ }^{\mathrm{a}, 1}$, Carlos Alexander Lucho-Constantino ${ }^{\mathrm{a}}$, Rosa Icela Beltrán- \\ Hernández ${ }^{\mathrm{a}^{*}}$ \\ a Área Académica de Química. Universidad Autónoma del Estado de Hidalgo/ Carr. Pachuca-Tulancingo km. 4.5, Col Carboneras, Mineral de la Reforma, Hidalgo,
} México.

\section{Resumen}

México figura dentro de los primeros quince países en donde han ocurrido los más grandes accidentes industriales entre 1917 y 2011. El accidente en la planta de agroquímicos Tekchem, ubicada en Salamanca, Guanajuato fue uno de los doce eventos acaecidos en nuestro país en el periodo mencionado. En este estudio se describe cómo este accidente forzó a las autoridades ambientales a prestar atención a un pasivo ambiental que se formó durante casi 50 años, mismo que hasta la fecha continúa sin ser totalmente remediado.

Palabras Clave: malatión, organoclorados, organofosforados, pasivo ambiental, emergencia ambiental.

\section{Introducción}

En México, la legislación ambiental referente a la contaminación del suelo comenzó a esbozarse a finales de la década de los 80. La Ley General de Equilibrio Ecológico y Protección al Ambiente (LGEEPA), publicada en 1988, no se refería de manera específica al suelo, solo establecía los principios básicos en torno a la responsabilidad de preservar el equilibrio ecológico, prevenir las causas de su deterioro y los elementos mínimos indispensables para elevar la calidad de vida de la población. Fue en 1996 que se reformaron algunos criterios de la LGEEPA para prevenir la contaminación del suelo y para recuperar aquellos que presentaban contaminación por materiales o residuos peligrosos. Posteriormente, en el año 2000 se publicó en el Diario Oficial de la Federación (DOF) una fracción reformada de la LGEEPA que hacía posible cuantificar el costo del daño ambiental anual y con este el Producto Interno Ecológico (DOF, 2000). Una posterior reforma, realizada en 2012, contemplaba además la obligación de prevenir, minimizar o reparar el daño ambiental, así como incentivos para quienes realizaran o promovieran acciones para proteger el medio ambiente o acciones de mitigación y adaptación a los efectos del cambio climático.

Actualmente, se cuenta con guías y criterios específicos para el muestreo, caracterización y recuperación de suelos contaminados, y es la Secretaría de Medio Ambiente y Recursos Naturales (SEMARNAT) el organismo encargado de atender la gestión de estos suelos.

De acuerdo con la legislación vigente en nuestro país existen dos escenarios posibles en cuestión de sitios contaminados: emergencias ambientales y pasivos ambientales (SEMARNAT, 2018a).

Una emergencia ambiental es una circunstancia o evento indeseado e inesperado, que resulta en la liberación no controlada, incendio o explosión de uno o varios materiales peligrosos o residuos peligrosos que afectan la salud humana y el ambiente de manera inmediata. En cambio, un pasivo ambiental es un sitio contaminado por la liberación de materiales o residuos peligrosos, que no fueron remediados oportunamente, pero que implican una obligación de remediación. Los pasivos ambientales incluyen también la contaminación generada por una emergencia que tenga efectos a largo plazo sobre el medio ambiente (SEMARNAT, 2018a).

En este artículo se hace una revisión sobre uno de los pasivos ambientales más importantes en nuestro país, el de la empresa Tekchem, el cual se generó como resultado de dos circunstancias: la acumulación de residuos peligrosos en la planta y una emergencia ambiental provocada por la fuga de un material peligroso.

\section{Cómo nació Tekchem}

Desde 1956, el predio ocupado por Tekchem, en Salamanca, Guanajuato, ha albergado industrias con distintos nombres, todas ellas dedicadas a la fabricación de plaguicidas. La primera de ellas fue Montrose Mexicana, cuyos productos de fabricación fueron hexacloruro de benceno (BHC) y diclorodifeniltricloroetano (DDT). Tres años después se instaló dentro del mismo predio Lerma Industrial para fabricar toxafeno. En 1968, las dos empresas anteriores fueron adquiridas por la paraestatal Guanos y Fertilizantes de México (Guanomex), en ese entonces la única empresa productora de plaguicidas organoclorados en México. Posteriormente Guanomex se convirtió en Fertimex (Fertilizantes Mexicanos), la cual agregó a lista de productos plaguicidas organofosforados: malatión y metilparatión, así como intermediarios para la síntesis de los mismos. Esta empresa paraestatal funcionó hasta 1992, cuando se privatizó y la unidad Salamanca fue vendida a VelPol. En 1996 VelPol se convirtió en Tekchem S.A. de C.V. y posteriormente en 2006 en Tekchem S.A.B. de C.V. (Albert y Jacott, 2015).

\footnotetext{
${ }^{1}$ ASCM y EOR contribuyeron en la misma medida para la realización de este artículo.
} 
Los principales productos elaborados por Tekchem eran plaguicidas organofosforados: malatión, metilparatión, metamidofos e intermediarios metílicos, toda vez que el DDT se produjo solo hasta 1997, mientras que el BHC y el toxafeno dejaron de producirse desde que Fertimex estuvo a cargo de la planta.

\section{La formación del pasivo ambiental por acumulación de residuos peligrosos}

Cuando VelPol adquirió Fertimex, la acumulación de residuos de los plaguicidas organoclorados y organofosforados que se habían fabricado ahí por 36 y 22 años, respectivamente, era evidente. Por ello, el Gobierno Federal liberó a VelPol de cualquier responsabilidad sobre los residuos existentes en el predio y destinó el dinero obtenido de la venta a un fideicomiso para la remediación del sitio. También se formó una comisión especial encargada de decidir qué acciones debería de contemplar el plan de remediación.

La presencia de contaminantes en el predio propiedad entonces de VelPol quedó asentada en la auditoría realizada por la Procuraduría Federal de Protección al Ambiente (PROFEPA) entre 1992 y 1993, la cual reportó un poco más de 84,000 toneladas de residuos peligrosos de DDT, BHC, toxafeno, mercurio y azufre. Unos años después se encontró que había otras 2,500 toneladas de residuos de BHC enterradas dentro del predio, ya que era una práctica común de Fertimex colocar los residuos de los plaguicidas organoclorados en tambos que eran enterrados dentro del predio, mientras que los residuos de los organofosforados se acumulaban sobre el suelo.

En 1994 se firmó un acuerdo entre la PROFEPA y VelPol para llevar a cabo las recomendaciones emitidas en la auditoría anteriormente mencionada y confinar debidamente los residuos peligrosos. Sin embargo, del total de residuos, solo 12,000 toneladas habían sido retiradas del predio para finales del 2000. Para tratar los suelos del predio se seleccionó la desorción térmica. Este método consiste en calentar el suelo en un reactor hasta lograr la volatilización de los contaminantes. Existen dos variantes de este tratamiento: de baja temperatura $\left(90-320{ }^{\circ} \mathrm{C}\right)$ y de alta temperatura $\left(320-560{ }^{\circ} \mathrm{C}\right)$. Para lograr la volatilización de los plaguicidas contaminantes debió usarse la segunda. Este método resultó inapropiado ya que los contaminantes presentes (i.e. DDT, toxafeno, paratión, malatión, mercurio, azufre, etcétera) forman gases tóxicos y corrosivos al ser calentados y algunos de ellos, como el paratión, son explosivos a altas temperaturas (ATDSR, 2016; NJH. 2011; INSHT, s.f.). Desde luego, un tratamiento por desorción térmica debe contar con una unidad para el tratamiento de los gases de combustión. Sin embargo, todo parece indicar que esta medida no se atendió, lo que ameritó que el Instituto Nacional de Ecología (INE en aquel entonces) determinara que en la planta de Tekchem existía una situación de riesgo ambiental que ameritaba medidas urgentes.

El suelo no era el único compartimento ambiental contaminado por la actividad industrial en Tekchem. Las quejas de los pobladores vecinos por los olores insoportables y los efectos de estos sobre la salud y el medio ambiente, eran una constante. Estas quejas nunca fueron realmente atendidas ya que los delegados de la PROFEPA argumentaron que no había una normatividad para regular los olores. Por la cercanía de la planta con el río Lerma, el agua también resultó contaminada (Albert y Jacott, 2015).

\section{La emergencia ambiental por una fuga de malatión}

El 12 de septiembre del 2000 ocurrieron tres explosiones en la planta de Tekchem: una a las 16:00 h, otra a las 19:00 h y la última a las 19:30 h. De la primera, la población solo escuchó la alarma, algo que se había vuelto común en los últimos días. La segunda explosión ocurrió media hora después de que sonara nuevamente la alarma y esta vez se generó una nube de aproximadamente $5 \mathrm{~km}$, que después el viento dispersó $17 \mathrm{~km}$ más hacia el sur, hasta el Valle de Santiago. Media hora más tarde se escuchó otra explosión más, que fue dirigida por el viento hacia el poniente, de tal suerte que los gases tóxicos atravesaron Salamanca y llegaron hasta Irapuato. Irónicamente, las personas afectadas por la primera explosión estaban siendo trasladadas hacia el poniente, por lo que cuando ocurrió la segunda explosión resultaron nuevamente expuestas. Fue hasta después de la tercera explosión que la empresa permitió el paso de los servicios de emergencia, ya que, según el director de la planta, creían que se trataba de un simple derrame que la brigada de emergencia de la empresa no pudo manejar.

Para controlar el accidente fue necesaria la participación de los cuerpos de seguridad de Salamanca y de once municipios más. Se evacuó a todas las personas que se encontraban en un radio de tres kilómetros, aunque muchas de ellas ya habían abandonado sus casas para cuando las autoridades tomaron acción. Pese a que la emergencia se declaró controlada a las 1:55 h del 13 de septiembre, el personal de rescate comenzó a regresar a las personas evacuadas a sus casas antes de que esto sucediera. Las indicaciones que recibió la población fueron ventilar las casas, lavar la ropa y los alimentos y darse una ducha. Según las recomendaciones del Departamento de Salud de New Jersey (NJH, por sus siglas en inglés, 2011), después de una exposición excesiva, los pacientes se deben vigilar durante las $24-48$ horas posteriores, debido a que existe riesgo de que se presente edema pulmonar tardío, que causaría falta excesiva de aire. La medida anterior no se aplicó a las personas afectadas por las explosiones en Tekchem, y se desconoce si se presentaron casos de edema pulmonar tardío.

De acuerdo con el diario El Salmantino, el reporte final de Teckchem reconocía que fueron 7.5 toneladas la cantidad de malatión involucrada en la fuga, cuando inicialmente la cantidad reportada había sido de 60 toneladas (El Salmantino, 2016). Tampoco hay certeza sobre el número de personas expuestas, se ha calculado que fueron 100,000 las que se encontraban en los alrededores más las de las comunidades rurales hacia donde se dirigieron las nubes de las explosiones, además de los 100 trabajadores que estaban laborando cuando ocurrió el accidente. El número de intoxicados varía entre 200 y 6000, según la fuente que se consulte. Los hospitalizados van desde ninguno hasta 800 y los que se declararon como enfermos graves van desde ninguno hasta 37. Los informes oficiales y de la propia empresa son los que reportaron las menores cifras: de uno a tres intoxicados en todo el estado, según el Boletín de Epidemiología de la Secretaría de Salud y ningún intoxicado, de acuerdo con el reporte de Tekchem a la Bolsa Mexicana de Valores (Albert y Jacott, 2015).

Entre los síntomas reportados por los afectados por el accidente, figuran problemas respiratorios diversos, dolor de 
cabeza, pérdida de consciencia momentos después de la explosión, dolor abdominal, náuseas, vómito, conjuntivitis, gastritis, así como una variedad de problemas de salud que los han aquejado años después de la exposición, incluso casos de cáncer (El Salmantino, 2016). Los síntomas y padecimientos expresados por los afectados coinciden en su mayoría con los efectos reportados para el malatión en la salud humana. Un estudio médico independiente encontró que no todos los síntomas coinciden con una intoxicación por malatión, lo que hace pensar que tal vez no fue este plaguicida el único contaminante en la explosión o ni siquiera el principal. El malatión está reconocido como un carcinógeno humano, y su exposición puede causar dolor de cabeza, mareo, visión borrosa, opresión en el pecho, sudor, náusea, vómito, diarrea, fasciculaciones, falta de coordinación, crisis epilépticas, coma, e incluso la muerte. La inhalación de este plaguicida puede causar tos y falta de aire por irritación del pulmón, y en concentraciones altas puede ocasionar edema pulmonar $(\mathrm{NJH}$, 2011).

Las causas que originaron el accidente tampoco se han esclarecido, según la versión final de la empresa se debió a fallas en una válvula.

Desafortunadamente aun cuando la planta de Tekchem cesó sus operaciones definitivamente en junio de 2008 los residuos continuaron en el predio, por aproximadamente ocho años más, a merced de la acción erosiva del agua y del viento que los diseminaba en los alrededores.

\section{5. ¿Qué ha pasado con el plan de remediación del predio de Tekchem?}

Durante el 2018 se publicaron algunas noticias en torno al avance de los trabajos de remediación del predio ocupado por Tekchem. El 31 de octubre de 2018, la SEMARNAT reportó que estaba en proceso la aprobación de los programas de remediación del predio y de los suelos contaminados, en tanto que la disposición final de los residuos ya se realizó en confinamientos controlados y autorizados. Además, se demolieron los edificios en los que se resguardaban los residuos. También se demolió la planta sosa cloro y se retiraron los residuos de asbesto. Finalmente se menciona que la remediación del suelo con concentraciones medianas corresponde a una segunda etapa de la que no se indica la fecha de inicio (SEMARNAT, 2018b).

\section{Conclusión}

Tekchem es un solo ejemplo de los numerosos pasivos ambientales que se encuentran en nuestro país y que afectan la salud del medio ambiente y de la población. Con el caso de Tekchem se ha demostrado cómo la ausencia de normatividad y la falta de aplicación de la existente hacen posible que las empresas operen sin atender los criterios mínimos de seguridad laboral y ambiental.

\section{English Summary}

An example of environmental malpractice: Tekchem in Salamanca, Gto.

\begin{abstract}
Mexico is among the first fifteen countries where the major industrial accidents had occurred between 1917 and 2011. The accident happened in Tekchem, an agrochemical plant located in Salamanca, Guanajuato, is one of the twelve events that occurred in our country in the mentioned period. In this study we describe how this accident forced the environmental authorities to pay attention to an environmental liability that was formed for almost 50 years, which until now continues without being totally remedied.
\end{abstract}

Keywords:

Malathion, organochlorines, organophosphates, environmental liability, environmental emergency.

\section{Referencias}

Albert, L. A., Jacott, M., 2015. México Tóxico: Emergencias Ambientales. Siglo XXI Editores. Ciudad de México.

ATSDR, 2016. Toxafeno. Recuperado de: https://www.atsdr.cdc.gov/es/toxfaqs/es_tfacts94.html. Fecha de consulta: 1 de noviembre de 2018.

DOF. 2000. DECRETO por el que se adiciona una fracción XXXVI al artículo 3o., la fracción XX al artículo 15 y se reforma el artículo 39 de la Ley General del Equilibrio Ecológico y la Protección al Ambiente.

INSHT, s.f. DDT: Diclorodifeniltricloroetano. Recuperado de: http://www.insht.es/InshtWeb/Contenidos/Documentacion/FichasTecn icas/FISQ/Ficheros/0a100/nspn0034.pdf. Fecha de consulta: 1 de noviembre de 2018.

NJH, 2011. Paratión. Hoja informativa sobre sustancias tóxicas. Derecho a saber. Recuperado de: https://nj.gov/health/eoh/rtkweb/documents/fs/1459sp.pdf. Fecha de consulta: 31 de octubre de 2018.

SEMARNAT, 2018a. Programa Nacional de Remediación de Sitios Contaminados, México, 2018, Recuperado de: https://www.gob.mx/semarnat/documentos/programa-nacional-deremediacion-de-sitios-contaminados, 17-08-2018.

SEMARNAT, 2018b. Remediación de Tekchem. Recuperado de: https://www.gob.mx/semarnat/acciones-y-programas/remediacion-detekchem

Tekchem a 16 años del daño ambiental y de salud, 12 de septiembre de 2016. El Salmantino. Recuperado de: http://salmantino.mx/2016tekchem-a-16-anos-del-dano-ambiental-y-de-salud/ 